\title{
Six Major Challenges Faced by Near-Death Experiencers
}

\author{
Yolaine M. Stout, B.A. \\ Alpine, $C A$ \\ Linda A. Jacquin, C.A.S. \\ Wentzville, $M O$ \\ P. M. H. Atwater, L.H.D. \\ Charlottesville, VA
}

\begin{abstract}
This article sheds more light on some of the unique personal and spiritual challenges that people face following near-death experiences (NDEs). The six challenges and suggested remedies described here were developed from more than 185 written responses to two questions, regarding challenges after NDEs and remedies, gathered from 25 attendees at the first retreat for NDErs held by the International Association for Near-Death Studies (IANDS), in April, 2006. We hope that this informal study will stimulate more formal research into the challenges and unique needs faced by all NDErs and the development of resources to assist experiencers in coping with them.
\end{abstract}

$K E Y$ WORDS: near-death experience; near-death experiencer; psychological challenges; spiritual challenges; integration; aftereffects; transformation.

The first retreat for near-death experiencers (NDErs) organized by the International Association for Near-Death Studies (IANDS) was held at Mercy Center in St. Louis, Missouri, April 17-20, 2006. The

Yolaine M. Stout, B.A., is a near-death experiencer (NDEr) and a strategic planner, writer, and professional life coach. She is Chair of Development and Strategic Planning on the Board of Directors and President-Elect of the International Association for NearDeath Studies (IANDS). Linda A. Jacquin, C.A.S., is the Editor of Vital Signs, former Vice President of IANDS, an NDEr, consultant, and lecturer on the near-death experience. P. M. H. Atwater, L.H.D., is an NDEr and a free-lance investigator, author, lecturer, and workshop facilitator whose principal interest has been near-death experiences and spiritual transformation. Reprint requests and should be sent to Ms. Stout at P.O. Box 2146, Alpine, CA 91903; e-mail: ystout11@cox.net. 
retreat was conceived by Linda Jacquin, former Vice President of IANDS and Editor of IANDS' newsletter Vital Signs, and herself an NDEr, who had long recognized the need for NDErs to bond and share their experiences, the meaning of the NDE, and its aftermath in a peer environment. The success of the retreat demonstrated the validity of the need to reflect collectively upon and share the experience and its challenges (Jacquin, 2006). Participants were able to express their experiences, some for the first time in their lives, among others who had "been there" and understood. Four of the participants had never spoken about their experience before strangers previously.

\section{Retreat Participants and Study Questions}

The retreat participants included 25 near-death experiencers from 15 different states. In a survey following the retreat, 12 of the 23 participants responding reported having had more than one NDE: 6 reported two NDEs each and 6 others reported three each. Three of the respondents reported suicide-related NDEs. Five had NDEs as children, of whom two had sudden recall of their childhood NDEs many years later as adults. One respondent reported a predominantly unpleasant (but not terrifying) experience during the second of her three NDEs, which occurred during attempted suicide in an attempt to return to where she had been in her first NDE. Two respondents stated that at the beginning of their NDEs they were fearful of what was happening. The remaining NDEs were described as "heavenly," "fulfilling," "transcendent," or "positive" experiences. Half of the respondents had experienced their NDEs 20 or more years prior to the retreat. The most recent NDE was 2 years prior to the retreat, the oldest 55 years prior, in childhood but never forgotten; that participant reported feeling profoundly impacted by the NDE for her entire life.

Seventeen respondents ( 74 percent) considered themselves welladjusted, having integrated their NDEs into their lives. They had to face these challenges when few, if any, resources were available to assist them, yet they managed not just to overcome these challenges, but to establish careers and/or become active in charitable work, social causes, and spiritual service.

With so many near-death experiencers together in one place, coming from all over the United States and representing a wide variety of backgrounds, organizers agreed that this would be a unique opportu- 
nity to collect valid information in the experiencers' own words that could be translated into useful tools to aid NDErs in the integration of the most transformative event in their lives. We therefore asked each of the 25 participants two questions: (a) what were the struggles or challenges that you faced following your NDE? and (b) what would help you or did help you with these challenges? The challenges described below took years to assimilate. As these personal challenges were overcome, participants found that they were increasingly able to focus on what they saw as their purpose in life, offering greater love and service to others.

Of the 115 challenges described by the experiencers at the retreat, 113 fell into one of six challenge areas. The areas are suggestive of a progression of stages that may or may not be experienced by all, and not necessarily in this order. If future study validates these stages, it may aid experiencers and those involved with their lives in preparing for and processing each stage. The stages may help to outline a type of "step program" for the integration of the NDE.

\section{Challenges Facing Near-Death Experiencers}

\section{First Challenge: Processing a Radical Shift in Reality}

Participants described the NDE as an unanticipated, dramatic, and complete immersion into a reality unlike anything experienced in their lives previously. Participants underwent what some described as a permanent and complete paradigm shift in reality and view of themselves, a sudden correction in their accustomed path and perspective on life.

Seventeen survey respondents ( 74 percent) described their experience as "more real than reality," with the remaining describing the experience as "equally real." In this "equally real" or "more real" dimension, several respondents underwent dramatic life reviews in which they were shown how their past behavior and values affected themselves and others. All but one respondent, who had had a childhood NDE, stated emphatically that they were changed and remained profoundly impacted by their NDEs.

Participants returned with a radically new concept of life, death, the afterlife, body, mind, and spirit. They reported that after this sudden shift in reality with a new view of self and life's purpose much time was needed to process the experience and all of its implications. 
Seventeen respondents who specified the time required averaged 12.7 years to adjust to the NDE. The longest reported adjustment time was 42 years, and five respondents stated that they were still adjusting. Many retreat experiencers expressed that they were still reeling from the impact of their experience decades afterwards. All but three respondents said that there was not a day that went by when they did not think of their NDE.

The time needed to process the NDE was accompanied by an intense yearning to understand the experience. One retreat participant described her search for understanding as "voracious." Respondents said they found relief through books or other sources when they discovered that their experience had a name and that they were not alone in having had an NDE.

\section{Second Challenge: Accepting the Return}

For 18 respondents ( 78 percent), the NDE was as "heavenly" as it was "more real than reality." Every one of the respondents said they had experienced pure, unconditional love in their NDEs. All but three felt they had experienced their true "home," their ultimate destiny. The remaining three described this as a "stopping point in our evolution," "the ultimate reality," and a place where "consciousness becomes pure." Other terms commonly used included "the home of all homes," "home base," "my origin," and "the Other Side." All but one stated that this experience was one of the "afterlife" and that everyone will experience "something like this" when they die. Several elaborated on this statement by saying that they caught only a glimpse, and that people will receive their own custom-designed experiences when they die. Additional descriptive comments included a place "where we will ultimately merge back into the Source," a "transition place until we move to another world," and "the next step in evolution."

When asked if they were afraid of death, all but two responded with an emphatic negative response. This "heavenly" place called "home" was perhaps the main reason that these participants said that not only did they no longer fear death, but they would rejoice when their time comes. In response to the question of how they would feel when they knew their time had come to die, responses ranged from "ecstatic" to "relief" to "acceptance." None said they would fear or deny death. 
Far from fearing death, 18 respondents (78 percent) had felt a yearning to return or felt "homesick." Among those 18, frequency of feeling homesick ranged form "all the time" to "bouts now and then." Four respondents ( 17 percent) felt a yearning for "home" that was so strong that they had considered suicide in order to return. One of those reported having attempted suicide, resulting in her second NDE, an unpleasant one. Another reported always harboring suicidal thoughts but being restrained from acting on them by fear and guilt. A third reported refraining from suicide because of a religious view of suicide as a mortal sin.

Eight respondents ( 35 percent) chose to return to life in at least one of their NDEs; whereas 14 (61 percent) were not given a choice, but were told they had to return or suddenly found themselves back in their bodies. Emotions about returning ranged from confusion, anger, fear, depression, disappointment, unhappiness, and rejection to acceptance, gratitude, relief, humility, and giddiness at the thought of being able to serve others. One respondent reported being not happy at all, but rather being on a 37-year quest to re-experience the blissful feelings of the NDE. Another described feeling "run over by God."

In addition to these powerful emotions, respondents still dealt with the physical pain, illness, and/or emotional traumas that led up to the NDE in the first place, which could acerbate any feelings of homesickness, sadness, or anger at being sent back. Fifteen respondents (65 percent) reported still dealing with health issues related to the circumstances that lead to their NDEs.

\section{Third Challenge: Sharing the Experience}

Participants' need to share their NDEs was intense. In the beginning, it was important not just to be believed and accepted, but also to share the experience in order to process and understand what happened. Accompanying that was a yearning to share their amazing journey, its joy, its love, its meaning, and its messages, especially with their loved ones. The challenge of sharing the experience was described by participants as fourfold.

Expressing the Ineffable. First, finding the words to express something for which there was no common comparison was a frustrating exercise. How could one describe the infinite, loving light that was 
so unforgettable? How could one describe a dimension that was more real than reality? How could one explain the experience of timelessness, all-knowing, and oneness with all that is, was, and ever will be? How could one describe colors and sounds that do not exist on Earth? Words fell pitifully short of the true experience. The inability to express these profound ideas left many respondents feeling that other people could never truly comprehend or believe them.

Choosing Confidants. The second related challenge was deciding if they should share the experience at all, and with whom. Who would understand? Only one of the 23 respondents (4 percent) sought a clinical therapist specifically to discuss the NDE. Three others had been in therapy for other reasons and had mentioned their NDEs. Four respondents said that their NDEs were "pathologized" by doctors or therapists. Afraid of sharing, one respondent kept the NDE, which had occurred at age 14, entirely suppressed for 36 years, while another kept silent about the experience for 42 years. Neither had shared the NDE even with family members. Others also described decades of silence. This challenge of sharing was perhaps the most acute for those who had attempted suicide or for those who had terrifying or distressing experiences. In a world where people have dismissed the NDE as a "dream," and where researchers or medical professionals have proclaimed the NDE a hallucination, an illusion of a dying, asphyxiated, medicated brain, respondents' fears were well justified.

Coping with Negative Reactions. The third related challenge was coping with the traumatic and isolating effects of having told this most precious experience to doctors, family members, or trusted friends who were dismissive, misunderstanding, patronizing or otherwise negative. Eighteen respondents ( 78 percent) described a very painful and/ or lasting consequence of having shared the experience with someone who did not want to hear about, believe, appreciate, or understand what happened. Two more had not suffered these consequences because they were either silent or extremely selective about whom they told. The fear, isolation, and loneliness felt by those who dared not share or had shared with someone who reacted negatively was one of the biggest challenges that participants described at the retreat. Typical comments included "My family didn't want me to talk about it," "My spouse discounted me," "My husband started making fun of me in front of his friends," and "My son was embarrassed when I 
talked about my NDE." Eighteen respondents (78 percent) reported feelings of alienation, isolation, or depression over the problems associated with no being able to share the experience.

Focus of Others' Interest. The fourth related challenge in sharing the NDE that retreat participants expressed was that when people did listen, they seemed interested in the experience itself, the details surrounding the manner of death, and the unusual aftereffects, while the very real personal, emotional, and spiritual needs of the experiencer were of lesser interest. It was perhaps for this reason that many participants felt that the only ones who could truly understand their personal challenges were other experiencers. Five respondents ( 22 percent) reported feeling most comfortable sharing with other experiencers, and five others (22 percent) felt most comfortable sharing at IANDS meetings or at the experiencer retreat. The remaining respondents said they were now comfortable sharing with anyone who expressed an interest and was openminded.

\section{Fourth Challenge: Integrating New Spiritual Values with Earthly Expectations}

The values, message, and meaning of the experience were often completely inconsistent with the participant's life prior to the experience, but the participant was compelled to align that inconsistent life with the new paradigm. As noted above, 100 percent of respondents reported feeling changed by the NDE. Typical comments included "I had to make do with a new life," "I was in tremendous pain over the reality of restructuring my life," "I had to put the pieces of my life back together in a new way," "It was a challenge of having inner knowledge and not knowing what to do with it," and "What do I do now?"

The universal message of the near-death experience for most retreat participants centered on the importance of unconditional love and how we treat each other on Earth. Fifteen respondents (65 percent) were given implicit instructions, guidance, warnings, lessons, prophecies, knowledge, or messages. Examples of these messages were "We need to spread light and love," "We can all be connected," "We are meant to live in peace and harmony," "We came here to learn about love," "We are immortal, "Love unconditionally," "We are here to learn and love," "Simply love," "At the core we are made of love," "We are here as emissaries of a higher spirit," "This life isn't all there is," "The only 
thing that is real is love energy," and "Love is everything and everything is love." Respondents reported feeling challenged, urged, or compelled to live up to these messages upon their return. All but one respondent, who was a childhood experiencer, said they had changed how they behaved towards others, becoming "more compassionate," "more forgiving," "more tolerant," "more loving," or "more empathetic."

These new outlooks, directions, and changes created friction in almost all important areas of participants' lives. The NDE affected relationships with others, careers, money, religion, and spirituality. Divorce and career changes brought on stressful emotional and financial upheaval, in addition to the other challenges participants faced. An example of an area of friction was the amount of time that participants reported volunteering, which was an average of 20 hours a week. Six respondents ( 26 percent) considered themselves fulltime volunteers. Of those who volunteered, 73 percent said they had experienced tension from family members for the amount of time and/ or money spent on charitable causes.

Thirteen of the 17 respondents who had divorced said their divorce was due at least in part to incompatibility over the values learned in their NDE. Typical comments included "I wouldn't react the same; money no longer mattered," "My unconditional love for others was misinterpreted," "I had knowledge that I couldn't relate to her," "My attitudes and values all changed," "It made me irritable to try to hold up my old person," "I couldn't communicate my deepest feelings and be understood," "My husband couldn't handle my new psychic abilities," and "I was told in my NDE that I would die of a heart attack if I did not get a divorce."

Fifteen respondents ( 65 percent) reported career changes. Eleven of these said the career change was due at least in part to their NDEs. Conflicting values and attitudes included "A position of power no longer meant anything to me," "I saw how my job was irrelevant," "I couldn't handle how they treated people," "They took earthbound things too seriously," "They saw me as weak," "I could no longer tolerate the avarice and greed," "I had a heightened intuition about what was happening and didn't dare speak the truth," and "It wasn't acceptable to talk about my NDE at work."

Many participants no longer held conventional views of heaven, hell, God, evil, or sin. Eighteen respondents (78 percent) said they had changed their attitude about their religious upbringing following their NDEs. The remaining five either had no religious upbringing or were 
childhood experiencers. Participants' new and often passionate views of spirituality and/or religion could evoke tension and even hostility among family members and religious followers. Some retreat participants described becoming "allergic" to traditional religious expectations, while others now found places of worship to be more comforting and affirming than ever before. In either case, a radical change in spiritual and religious views often alienated the participant from family, friends, and their traditional religious community. Typical comments included "I am no longer religious; I am spiritual," "There is some truth in all religions," "I don't like the dogma of traditional religions," "Religions create barriers," "I was totally deceived by my religious upbringing," "I look for spirituality in all religions," "The NDE became my basis of comparison," "I was an atheist; Man, was I wrong," "I love all religions," "My religion caused me anxiety; my NDE gave me peace," "Some fundamentalists think I was under the influence of Satan," and "I see God in everything."

With a change in conventional religious views, all but three respondents became involved in spiritual or NDE-related causes. Sixteen (70 percent) became actively involved in physical, emotional, and/or spiritual healing work, with nine of these working fulltime as physicians, ministers, therapists, self-help writers, counselors, or related professionals. Five were involved in some capacity in building or working in mind/body/spirit centers. Many were involved with IANDS as local support group leaders or directors.

Views towards social issues of violence, prejudice, disease, poverty, or justice often became very pronounced after the NDE. Changes in political or social views could bring additional tensions to relationships with spouses, family members, and friends who once shared similar views. As a result of all these conflicts and changes, participants often retreated into isolation and depression. Participants sometimes felt as if they no longer fit in, like strangers in an alien world where few people understood or believed them.

\section{Fifth Challenge: Adjusting to Heightened Sensitivities and Supernatural Gifts}

Among the changes they underwent following their NDEs, retreat participants described the challenge of adjusting to heightened sensitivities and supernatural or psychic gifts, not all of which were welcomed. Eighteen respondents (78 percent) said that these height- 
ened sensitivities or gifts had caused them problems. Seventeen ( 74 percent) said they had felt "ungrounded" from time to time, although all had found means to "ground" themselves.

Heightened Awareness and Sensitivities. Every one of the respondents reported a heightened awareness and sensitivity toward strong emotions and negative behaviors. Two respondents $(9$ percent) reported specifically that they were now empathic. One reported experiencing "physical pain" caused by others' negative emotions or behaviors. Typical comments included "I had to be alone with my sensitivities a lot; this caused a problem with my relationships," "It's hard for other people to understand why I am so sensitive," "Lying behavior is most troublesome," "I feel other people's pain," "I would pick up on people's anxiety and get stomach problems," and "I walk out of places that feel evil."

Nineteen respondents ( 83 percent) reported being more acutely aware of smells, visions, tastes, sounds, and/or touch. Although these questions were not specifically asked in the survey, two respondents reported hearing different frequencies and two mentioned a higher sensitivity to chemicals. Nineteen (83 percent) reported a heightened awareness or sensitivity to electricity, energetic fields, chi, and/or auras.

Due to these supersensitivities, respondents described difficulty readjusting to previously "normal" environments, job settings, situations, and events. The sensitivity toward electricity or energetic fields could be so intense that respondents said they could not work with computers, wear watches, or be around electrical devices. Twenty respondents (87 percent) said they believed that such devices malfunctioned in their presence, and several mentioned feeling uncomfortable around any event, device, or person that generated "negative energy."

Supernatural Gifts. In addition to these heightened sensitivities following an NDE, 19 respondents (83 percent) said that they had developed one or more supernatural gifts as a result of their NDEs. The gifts mentioned included intuitive, auditory, or visual knowledge of what was or what was to come (17 respondents, or 74 percent); ability to heal through energy work or laying on of hands (5 respondents, or 22 percent); mediumship (3 respondents, or 13 percent); telepathy ( 3 respondents, or 3 percent); seeing auras ( 2 respondents, or 8 percent), ability to communicate with animals (1 
respondent, or 4 percent); and automatic writing ( 1 respondent, or 4 percent).

While many people may embrace or seek these gifts, that was not necessarily the case with retreat participants. These gifts could surprise and disrupt the experiencer's customary thought processes and actions. Some learned to adjust their lives and careers to accept the gifts, while others described praying to be "left alone." One respondent said, "It drove me crazy because I didn't know what to do with it, so I closed it down." Another said, "Initially, it was frightening." Still another commented, "I worked hard to get rid of these sensitivities and psychic gifts; it felt like I was being punched."

\section{Sixth Challenge: Finding and Living One's Purpose}

Participants often struggled not just with the fact that they were sent back, but also with the reason for it. Every one of the respondents said they believed there was a reason they had been returned to this life and this reality. Twelve respondents (52 percent) were told specifically they had a purpose, but only four of those were told what it was, leaving 19 respondents ( 85 percent) to find it out on their own. One respondent stated that it took 20 years to identify it. Even though 20 respondents (91 percent) said they now relied on some form of guidance or intuition to make their decisions, 6 (26 percent) said they were still struggling to find their purpose in life. Most respondents seemed to be in agreement that, in general, we are here to serve and show unconditional love - a pretty tall order, but short on specifics and difficulty to apply.

All but one respondent (96 percent) said they believed that everything happens for a reason, although 9 (39 percent) said they did not know what those reasons were or that they did not need to know. The respondents who believed they understood why there is suffering on Earth offered comments like "We chose our lessons," "It's all homework," "It's not the experience but how we respond to it," "We manifest our own disasters," "To keep us on the path," and "In order to appreciate life more, we must experience loss." These beliefs often ran counter to traditional religious views, but seemed consistent among respondents.

The majority of respondents (61 percent) said they felt an urgent need to live according to the message or values learned in the NDE. 
Four respondents (17 percent) said they were afraid of not living accordingly or fulfilling their mission.

\section{Summary}

All of the respondents agreed that these six challenges generally summed up the major issues faced by near-death experiencers, although some of these challenges overlapped. When asked which of these six was the most challenging for them, 8 respondents (35 percent) chose integrating new spiritual values with Earthly expectations, 7 (30 percent) chose sharing the experience, 4 (17 percent) each chose adjusting to heightened sensitivities and supernatural gifts and finding and living one's purpose, and 2 (9 percent) each chose processing a radical shift in reality and accepting the return.

\section{Suggested Remedies}

Retreat participants expressed repeatedly the importance of IANDS in helping them with their challenges. The following is a consolidated brainstormed list of the remedies provided by retreat participants, resources that did help or that would have helped. We present this list in the hope that it will stimulate ideas for the creation of new resources and will validate and confirm existing sources.

Resources that participants said did help or would have helped included (a) informed, inviting, and understanding medical professionals; (b) a source for information on research, comparisons with mystical traditions, historical perspectives, personal experiences, and aftereffects, such as books, websites, or other media; (c) time to process, meditate, be in nature, or pray; (d) informed and understanding spouses, family, and friends; (e) guides, mentors, integration partners, spiritual counselors, trained clergy, spiritual psychologists, and informed marriage and family counselors, ideally but not necessarily NDErs themselves; (f) workshops, retreats, support groups, step programs, conferences, online support groups, classęs, and groups with experiencers; (g) self-help materials; (h) greater public awareness about NDEs; (i) venues to learn, speak, write, network, connect, and integrate the NDE into careers or 
volunteer work on matters related to the $\mathrm{NDE}$; and $(\mathrm{j})$ a retreat for childhood NDErs.

\section{Discussion}

More than two decades ago, IANDS sponsored a five-day conference on Clinical Approaches to the Near-Death Experience, in which 32 physicians, nurses, counselors, clergy, and other clinicians, one-third of whom were also NDErs, shared therapeutic strategies and techniques that they had found effective in helping experiencers (Greyson and Harris, 1987). Since then, others have written extensively about the difficulties experiencers often face integrating the NDE and its aftereffects into their lives (Atwater, 1988; Ring, 1980), and about the rationale for various approaches that respect both the experience and the experiencer (Miller, 1987), including the particular challenges associated with frightening NDEs (Bush, 2002). The retreat described in this report was the first organized gathering solely of experiencers that included an explicit intent to explore the challenges they face.

In conducting this informal study, certain questions arose that should be addressed in future surveys or formal needs assessments. It became apparent in this study that the needs of childhood, teenage, and adult near-death experiencers were not the same. Furthermore, since several respondents had had multiple NDEs, it was difficult to determine to what degree the challenges may have matched the content of the experiences. Perhaps the challenges of those who had multiple NDEs differ from those who had only one. An additional limitation of this study was that many of the NDEs occurred decades prior to the retreat. It is possible that over the course of years some challenges had been forgotten or underemphasized. Alternatively, experiencers with more recent NDEs may not yet have experienced all the challenges due to the lengthy time required to integrate the experience.

Additional areas that should be explored in future research include particular effects of having one's NDE pathologized by health or counseling professionals, lasting effects of remaining silent about the NDE, whether "ego-inflation" may result from an NDE, best resources for alleviating each of these challenges, and kinds of new resources needed to help alleviate these challenges.

We hope that this study will result in more research and the development of tools to aid the experiencer. Through study of the 
challenges such as outlined here, as well as the positive transformations that take place in an NDEr, we can validate the NDE and elucidate its dramatic power to affect people's lives.

\section{References}

Atwater, P. M. H. (1988). Coming back to life: The after-effects of the near-death experience. New York, NY: Ballantine Books.

Bush, N. E. (2002). Afterward: Making meaning of a frightening near-death experience. Journal of Near-Death Studies, 21, 99-133.

Greyson, B., and Harris, B. (1987). Clinical approaches to the near-death experiencer. Journal of Near-Death Studies, 6, 41-52.

Jacquin, L. (2006). Near-death experiencer retreat. Vital Signs, 25(2), 1 and 6.

Miller, J. (1987). A counseling approach to assist near-death experiencers: A response to Bette Furn's paper. Journal of Near-Death Studies, 6, 30-40.

Ring, K. (1980). Life at death: A scientific investigation of the near-death experience. New York, NY: Coward, McCann and Geoghegan. 